\title{
Prostaglandin Protection of Human Isolated Gastric Glands against Indomethacin and Ethanol Injury

\author{
Evidence for Direct Cellular Action of Prostaglandin
}

\author{
Andrzej Tarnawski, Tomasz Brzozowski, I. James Sarfeh, William J. Krause, Thomas R. Ulich, \\ Hella Gergely, and Daniel Hollander \\ Veterans Administration Medical Center, Long Beach, California 90822; Department of Medicine, Surgery and Pathology, University \\ of California, Irvine, California 92717; and Department of Anatomy, University of Missouri, Columbia, Missouri 65212
}

\begin{abstract}
Isolated human gastric glands from surgical specimens were preincubated in an oxygenated medium with placebo or 16,16 dimethyl prostaglandin $\mathrm{E}_{2}\left(\mathrm{dmPGE}_{2}\right)$ and incubated at $37^{\circ} \mathrm{C}$ in either medium alone, medium containing $4.43 \mathrm{mM}$ indomethacin or medium containing $8 \%$ ethanol. We assessed the viability of gland cells with fast green exclusion, release of lactate dehydrogenase (LDH) into the medium, and ultrastructural damage by scanning and transmission electron microscopy. Both indomethacin and ethanol significantly reduced the viability of placebo-pretreated glands, increased LDH release into the medium, and produced prominent ultrastructural damage. DmPGE 2 significantly reduced both indomethacin and ethanol-induced injury, increased the number of viable cells, reduced LDH release, and diminished the extent of ultrastructural damage. These studies indicate that PG protection of gastric mucosal cells has a direct cellular action that is not limited to replacement of depleted endogenous PGs. PG protection in our experiments did not depend on PG's previously described systemic actions, such as protection of the microvessels, preservation of the mucosal blood flow, or stimulation of bicarbonate and mucus secretion.
\end{abstract}

\section{Introduction}

Gastrointestinal mucosa is very active in the production of endogenous PGs from their precursors, dietary essential fatty acids (1). Mucosal generation of PGs and their release into the gastric lumen upon vagal or hormonal stimulation (2) may play an important role in local control of various gastric mucosal functions and in maintaining mucosal integrity (3-5). The discovery that aspirin and other nonsteroidal antiinflammatory drugs significantly inhibit formation of PGs (6-8) provided insight into the mechanisms of antiinflammatory action of nonsteroidal antiinflammatory drugs

Preliminary work was presented in part at the Annual Meeting of the American Gastroenterological Association, San Francisco, May 1986.

Address reprint requests to Dr. A. Tarnawski, Gastroenterology Section, Veterans Administration Medical Center, rm. 151, 5901 East Seventh Street, Long Beach, CA 90822.

Dr. Brzozowski was a visiting scientist from the Department of Physiology, University Medical School, Krakow, Poland.

Received for publication 12 March 1987 and in revised form 10 October 1987.

J. Clin. Invest.

(c) The American Society for Clinical Investigation, Inc.

$0021-9738 / 88 / 04 / 1081 / 09 \$ 2.00$

Volume 81, April 1988, 1081-1089 and their gastrointestinal side effects, which could result from mucosal PGs' deficiency.

When administered in vivo, PGs protect the gastric mucosa against necrosis produced by various noxious agents (3-5, 8-14), including indomethacin (8-13), aspirin (12), and ethanol $(3-5,14)$. This PGs' action appears to be independent of their ability to inhibit gastric acid secretion, and is generally referred to as cytoprotection or mucosal protection $(3-5,9$, 10). Stimulation of mucus and bicarbonate secretion, maintenance of mucosal blood flow, preservation of cellular ion transport, and protection of the mucosal proliferative zone have been postulated as potential systemic mechanisms responsible for the protective action of PGs $(3-5,9,10,14)$. While protection of the vascular endothelium (15) and maintenance of the mucosal blood flow (16) are well-documented components of PGs' protection, especially against ethanol injury, the possibility that PGs can directly interact with and protect the gastric mucosal cells in the absence of mucus, bicarbonate, blood flow, and other systemic factors has only been tested in the rat with inconclusive results (17) and has remained unexplored in man.

We used isolated human gastric glands to determine if PGs have a direct protective action on gastric mucosal cells. Because this unique in vitro gastric gland preparation excludes vascular and extraglandular neural as well as hormonal factors, it allowed us to assess the direct unmediated effects of pharmacological compounds on the mucosal cells. In this preparation we tested whether 16,16 dimethyl prostaglandin $\mathrm{E}_{2}(\mathrm{dmPGE})^{1}$ can protect isolated human gastric glands against either indomethacin, a damaging agent that inhibits endogenous PG synthesis or against ethanol, an agent that does not inhibit PG synthesis. As parameters of injury and protection we assessed the viability of gastric gland cells using a dye exclusion technique, lactate dehydrogenase (LDH) release into the medium, and scanning and transmission electron microscopy (EM).

\section{Methods}

The study has been approved by the Institutional Human Research Review Committee. Full-thickness surgical specimens of gastric wall were obtained from 16 patients who had $(a)$ gastric carcinoma $(n=5)$, (b) peptic ulcer $(n=7),(c)$ pancreatic carcinoma $(n=3)$, and $(d)$ esophageal carcinoma $(n=1)$. All specimens of oxyntic mucosa were obtained from the gastric resection line of grossly normal tissue. 15 specimens confirmed by subsequent histologic evaluation to contain both parietal and chief cells and to be free of tumor, ulceration, erosions, intramucosal hemorrhage, and/or prominent inflammatory in-

1. Abbreviations used in this paper: $\mathrm{dmPGE}_{2}, 16,16$ dimethyl prostaglandin $\mathrm{E}_{2}$; EM, electron microscopy; IND, indomethacin; LDH, lactate dehydrogenase. 
filtration were included in the study. To avoid prolonged mucosal anoxia, the specimens were obtained immediately after transection of the stomach. They were immersed in oxygenated PBS at $4^{\circ} \mathrm{C}$ and delivered to the laboratory within $5 \mathrm{~min}$ of excision. The average size of tissue specimens was $1.5 \times 1 \mathrm{~cm}$.

Gastric glands were prepared according to the modified method of Berglindh and co-workers $(18,19)$. In brief, the gastric mucosa was scraped, minced with scissors, and digested by $178 \mathrm{U} / \mathrm{mg}$ collagenase (Gibco Lab. Life Technologies, Inc., Grand Island, NY) $1 \mathrm{mg} / \mathrm{ml}$ in incubation solution. During digestion, gastric mucosal mince was slowly stirred with a motorized stirrer (VirTis Company, Gardiner, NY). After $40 \mathrm{~min}$ of incubation, the suspension was filtered through polypropylene mesh $(250 \mu \mathrm{m})$ to remove coarse fragments. The glands were harvested in calibrated conical tubes and washed three times with incubating medium (without collagenase) and centrifuged at $200 \mathrm{~g}$ for $1 \mathrm{~min}$ to remove residual collagenase. Finally, pellets were resuspended in $20 \mathrm{ml}$ of oxygenated incubating medium, $\mathrm{pH} 7.4$, containing 132.4 $\mathrm{mM} \mathrm{NaCl} ; 5.4 \mathrm{mM} \mathrm{KCl} ; 5.0 \mathrm{mM} \mathrm{Na} 2 \mathrm{HPO}_{4} ; 1.0 \mathrm{mM} \mathrm{NaH}_{2} \mathrm{PO}_{4} ; 1.2$ $\mathrm{mM} \mathrm{MgSO}_{4} ;$ and $1.0 \mathrm{mM} \mathrm{CaCl}_{2}$. The medium also contained $2 \mathrm{mg} / \mathrm{ml}$ BSA and $10 \mu \mathrm{g} / \mathrm{ml}$ phenol red. The resultant gland suspension contained $\sim 0.75 \times 10^{5}$ glands per $1 \mathrm{ml}$ of medium.

Standardized aliquots of isolated gastric glands were preincubated for $30 \mathrm{~min}$ at $37^{\circ} \mathrm{C}$ in $(a)$ oxygenated medium only as a control, or oxygenated medium containing either $(b) 0.025 \%$ ethanol as a solvent for PG (placebo) or (c) 0.52 or $2.6 \mu \mathrm{M} \mathrm{dmPGE}$ (gift of Dr. M. Ruwart and Dr. D. R. Morton Jr.; Upjohn Co., Kalamazoo, MI). After $30 \mathrm{~min}$ of incubation, glands were centrifuged, washed twice with $2 \mathrm{ml}$ of fresh medium, and resuspended in $1 \mathrm{ml}$ of oxygenated medium alone or medium containing either $4.43 \mathrm{mM}$ indomethacin (Sigma Chemical Co., St. Louis, MO) or $8 \% \mathrm{vol} / \mathrm{vol}$ ethanol. Glands were then incubated at $37^{\circ} \mathrm{C}$ for $1 \mathrm{~h}$ for ethanol experiments and for $2 \mathrm{~h}$ for indomethacin experiments. In additional experiments, we preincubated glands with $26 \mu \mathrm{M}$ dmPGE 2 followed by incubation with medium or medium containing $4.43 \mathrm{mM}$ indomethacin for $2 \mathrm{~h}$. The concentrations of

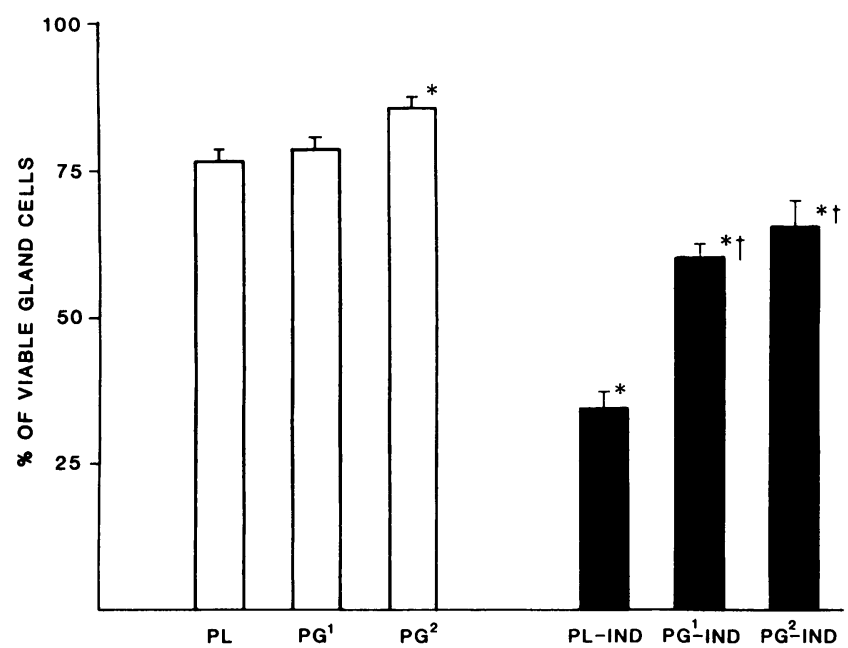

Figure 1. Viability of isolated gastric gland cells determined by fast green exclusion test. Each bar represents mean \pm SE of 12 separate gland preparations. White bars indicate experiments in which glands were incubated with placebo (PL) or $\mathrm{dmPEG}_{2}: 0.52 \mu \mathrm{M},\left(\mathrm{PG}^{1}\right) ; 2.6$ $\mu \mathrm{M},\left(\mathbf{P G}^{2}\right)$ without indomethacin. Black bars indicate experiments in which glands were preincubated with PL or PG and incubated with $4.43 \mathrm{mM}$ indomethacin (IND) for $2 \mathrm{~h} .{ }^{*} P<0.01$ vs. placebo, $+P$ $<0.001$ vs. PL-IND group. In addition to comparison of absolute values between the groups, the difference (delta)[PL - (PL-IND] was compared with differences $\left[\mathrm{PG}^{1}-\left(\mathrm{PG}^{1}-\mathrm{IND}\right)\right]$ and $\left[\mathrm{PG}^{2}-\left(\mathrm{PG}^{2}-\right.\right.$ IND], respectively. The $P$ values for these comparisons were also statistically significant $(P<0.01)$. indomethacin and ethanol were selected on the basis of our previous experiments with isolated rat gastric glands (unpublished data), which showed that these concentrations of indomethacin and ethanol reduced gastric gland viability by $>50 \%$ within $1-2 \mathrm{~h}$.

\section{Studies}

Cell viability. Cell viability was determined using fast green exclusion according to the method described by Weisenthal (20). This method is based on the fact that viable cells are able to exclude the dye while dead cells lose this ability. To $0.2 \mathrm{ml}$ suspension of glands with $\sim 0.75 \times 10^{5}$ glands $/ \mathrm{ml}$, an equal volume of $2 \%$ fast green (Sigma Chemical Co.) in $0.15 \mathrm{M} \mathrm{NaCl}$ solution was added. After $10 \mathrm{~min}$ the solution was mixed gently and added to the chamber of Cytospin centrifuge (Shandon Southern Instruments, Inc., Sewickley, PA) and centrifuged for $10 \mathrm{~min}$ at $200 \mathrm{~g}$. The resulting slides were then counterstained with hematoxylin and eosine and covered with cover glass using mounting balsam (National Diagnostics, Inc., Somerville, NJ). With this method, viable cells (i.e., cells excluding fast green) were stained pink with eosin while dead cells were unable to exclude the dye and therefore had nuclei and/or cytoplasm stained green. Coded slides were evaluated and counted under a Nikon Optiphot light microscope (magnification of 200 ) by two investigators unaware of the code. A minimum of 10 fields and 1,000 cells were counted per slide. The viability was expressed as the percentage of viable cells in 10 microscopic fields.

$L D H$. LDH release into the medium, an index of membrane damage, was measured using spectrophotometric assay with pyruvate and $\mathrm{NADH}$ as the substrate (21). After completion of the experiment, $0.8-\mathrm{ml}$ samples of incubating medium were taken for LDH assay. To determine total LDH activity in the gastric gland cells, 1-ml samples of

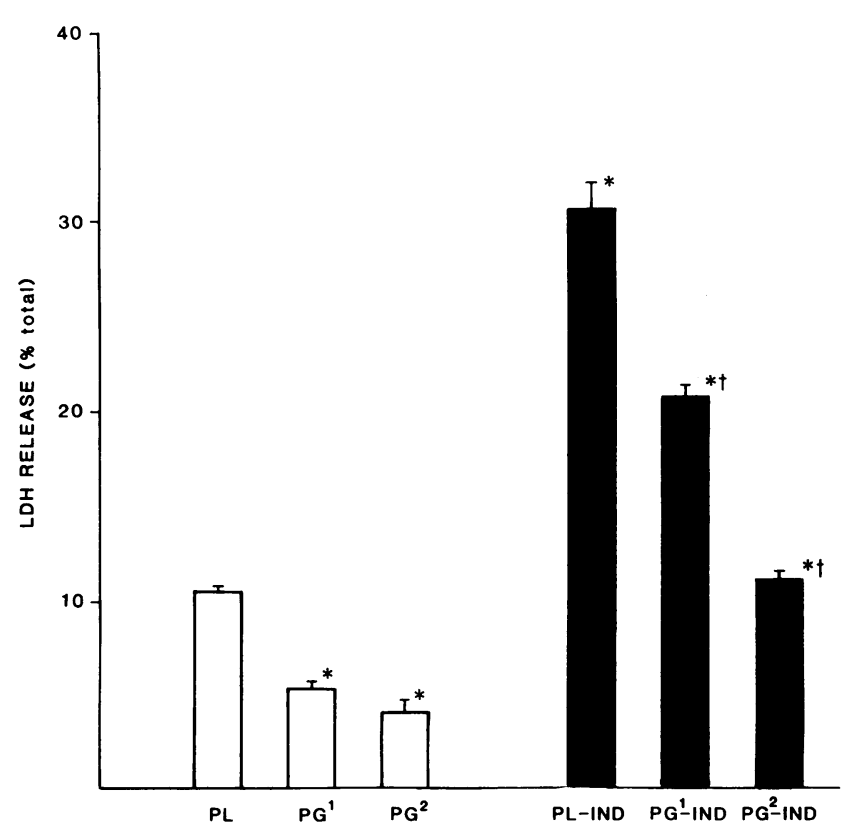

Figure 2. LDH release into the medium expressed a percent of total LDH contents in the glands. Each point represents mean \pm SE of 12 separate gland preparations. White bars indicate experiments in which glands were incubated with PL or $16,16 \mathrm{dmPGE}_{2}: 0.52 \mu \mathrm{M}$, $\left(\mathrm{PG}^{1}\right) ; 2.6 \mu \mathrm{M},\left(\mathrm{PG}^{2}\right)$ without IND. Black bars indicate experiments in which glands were preincubated with PL or PG and incubated with $4.43 \mathrm{mM}$ IND for $2 \mathrm{~h} .{ }^{*} P<0.01$ vs. placebo, $+P<0.001$ vs. PL-IND group. In addition to comparison of absolute values between the groups, the difference (delta)[PL - (PL-IND] was compared with differences $\left[\mathrm{PG}^{1}-\left(\mathrm{PG}^{1}-\mathrm{IND}\right)\right]$ and $\left[\mathrm{PG}^{2}-\left(\mathrm{PG}^{2}-\mathrm{IND}\right]\right.$, respectively. The $P$ values for these comparisons were also statistically significant $(P<0.01)$. 

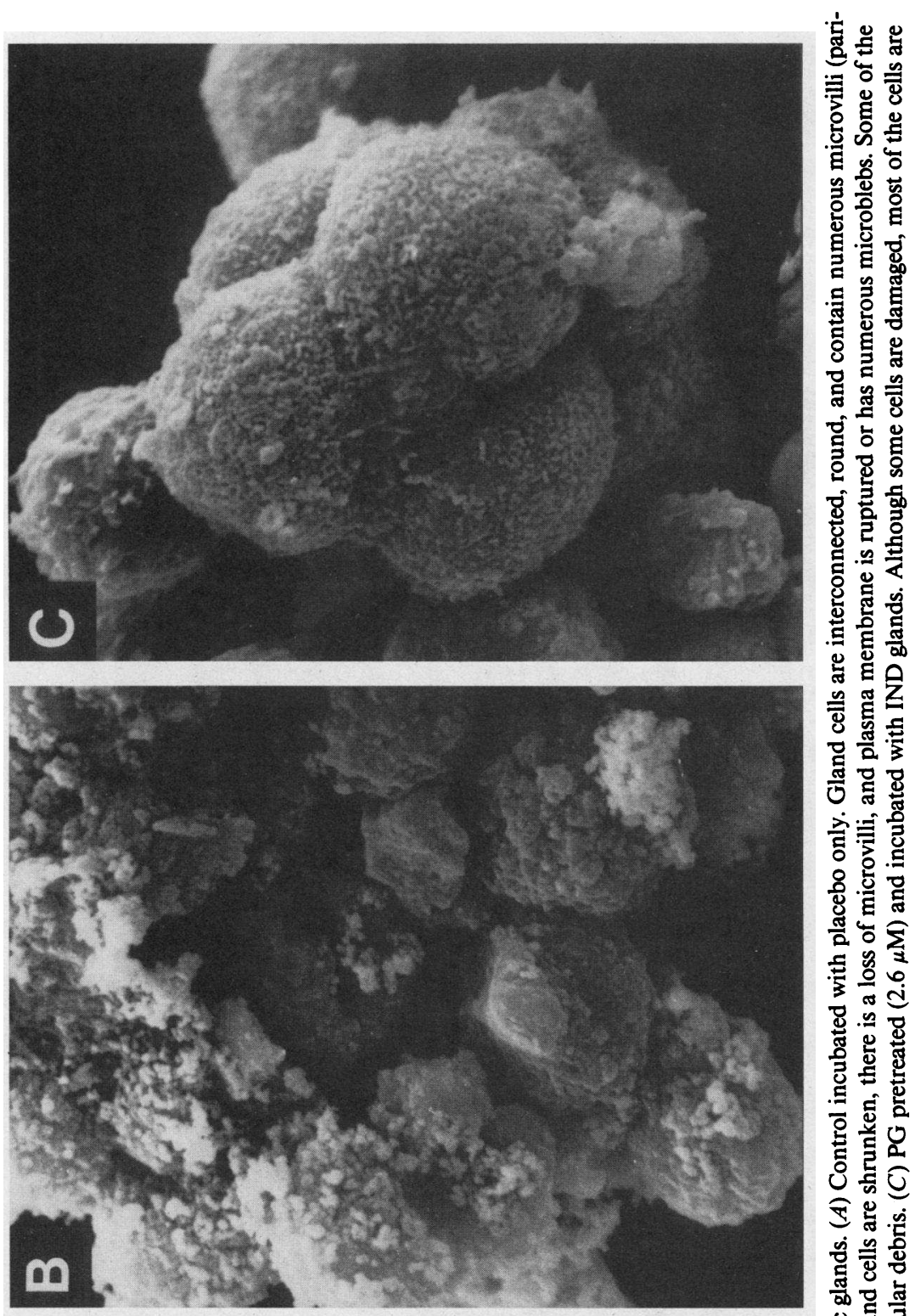

政 E \% 要

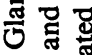

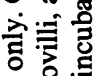
\& 总 壱 $\frac{\pi}{\pi}$ $\bar{g}$. 苞 竞 힙 잉

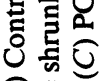
उิ ซึ कू 0 選

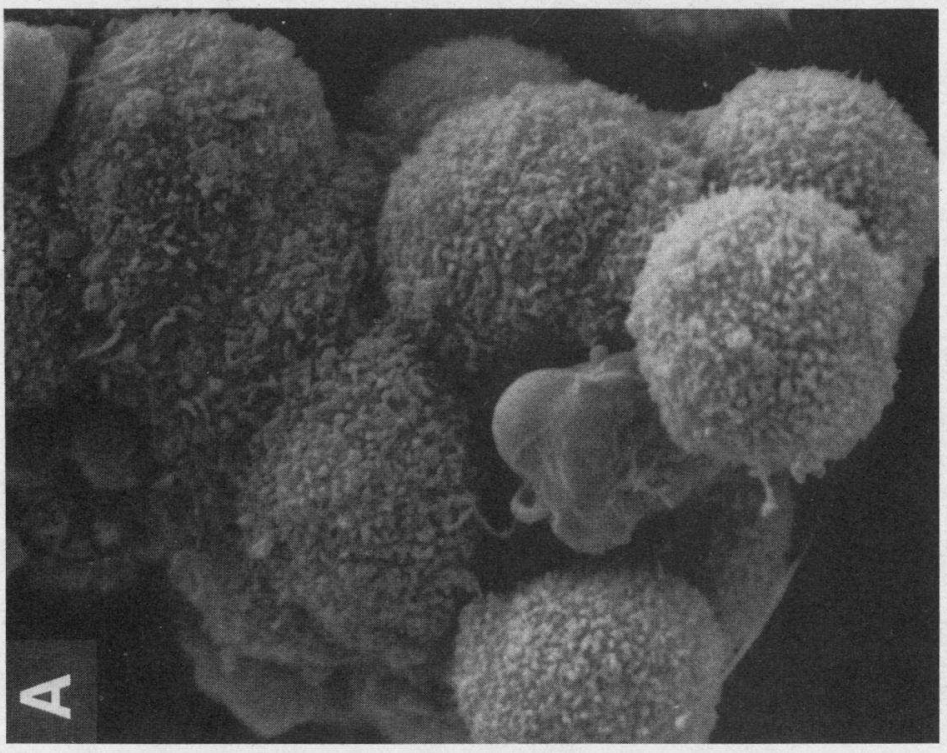

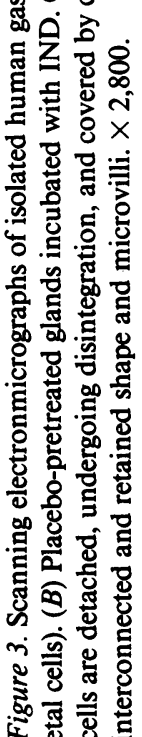




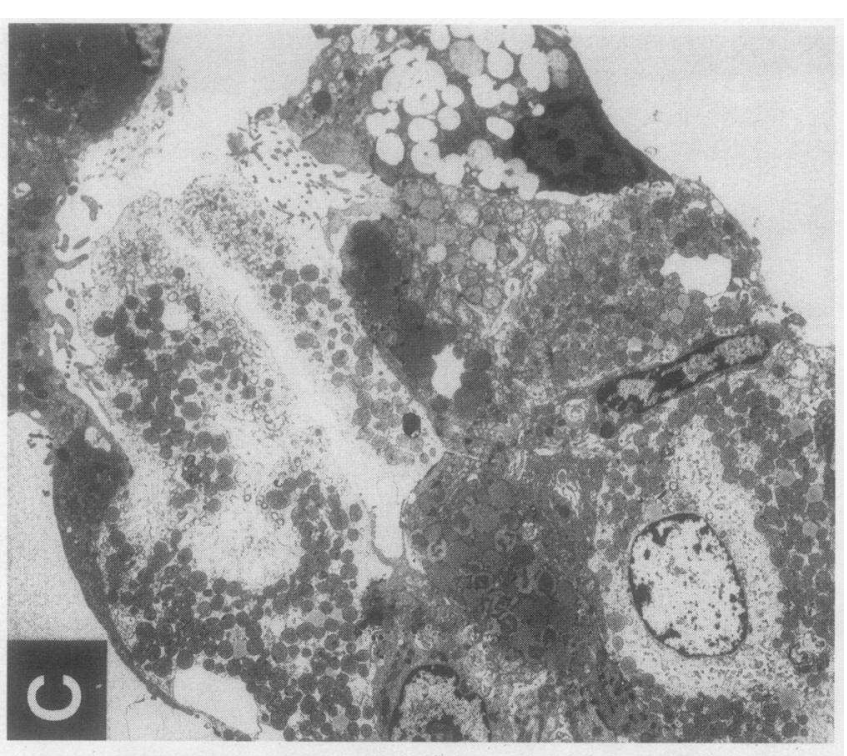

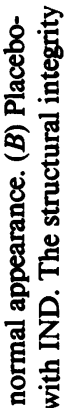

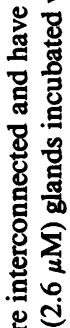
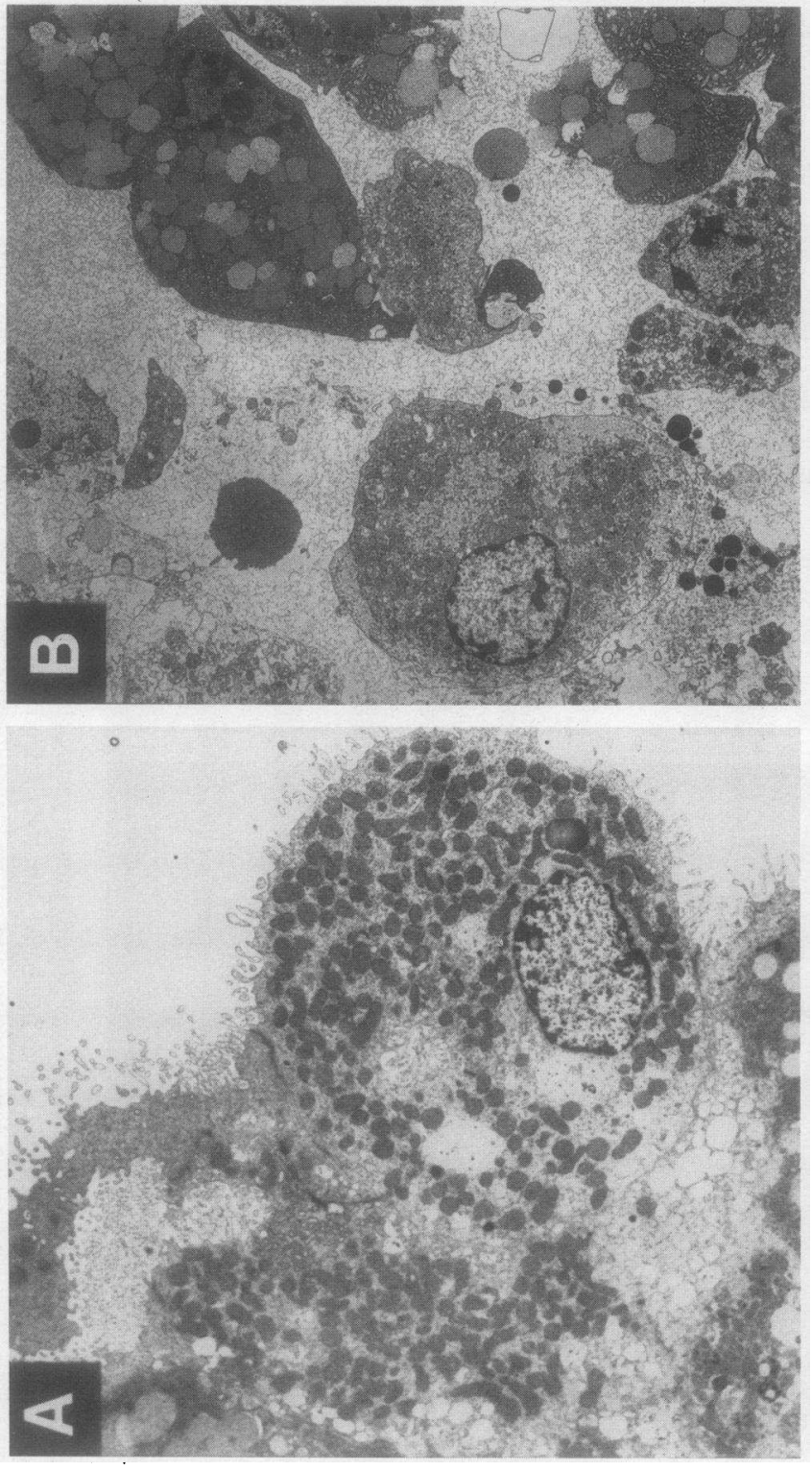

过

衣号

80

명

点

उ

줄

离

홍

ठิ ฮే

उ

형

행

.

嵒

ธี

8

롱

행

¿

产

舠 $x$

送

봉

政

ब

을

然

를

क

$\forall$.

密 
gland suspension taken at 0 time (before incubation) were sonicated to disintegrate the cells and LDH activity was measured. LDH release into the incubating medium was expressed as percentage of total LDH activity present in the glands at the beginning of incubation ( 0 time).

Scanning EM. Samples of gastric glands were taken at the end of each experiment and fixed immediately in $2 \mathrm{ml}$ of $3.5 \%$ glutaraldehyde (Polysciences Inc., Warrington, PA) buffered with $0.1 \mathrm{M}$ phosphate buffer to $\mathrm{pH} 7.4$ at $4^{\circ} \mathrm{C}$ and processed routinely for scanning EM (22). Coded specimens were viewed in JEOL-35 and Nanolab 10 scanning electron microscopes operated at $20 \mathrm{kV}$. Three specimens from each group were evaluated for ultrastructural features of cell damage.

Transmission EM. Samples of gastric glands were taken at the end of each experiment and fixed in $3.5 \%$ glutaraldehyde at $\mathrm{pH} 7.4$ at $4^{\circ} \mathrm{C}$ for $4 \mathrm{~h}$ and processed routinely for transmission EM (14). Coded sections were examined with Philips 400 and Zeiss 10 electron microscopes operated at $60 \mathrm{kV}$. Three specimens from each group were evaluated for ultrastructural features of cell damage.

Statistical analysis. All experiments were performed in duplicates from each gland preparation. The reported values are mean \pm SEM of all preparations. Statistical comparisons of cell viability and LDH release were performed with the Kruskal Wallis test (23). In addition to comparison of absolute values for the cell viability and LDH release between the groups, the difference (delta) [placebo alone - (placebo + indomethacin)] was compared with the difference (delta) [PG alone - (PG + indomethacin)]. Similar comparisons of deltas were also made for the ethanol groups. This was done to take into account possible effect of PG alone on the cell viability and $\mathrm{LDH}$ release. Statistical comparisons of differences (deltas) were performed with the Kruskal Wallis test (23).

\section{Results}

2-h incubation of placebo-pretreated isolated human gastric glands with indomethacin resulted in a significant reduction of viability of gland cells assessed by fast green exclusion (Fig. 1) and a significant increase of $\mathrm{LDH}$ release into the medium (Fig. 2). Scanning EM, when compared with controls (Fig. 3 $A$ ), showed severe damage and disintegration of the glands, detachment of the cells, loss of cellular shape, and loss of microvilli (Fig. 3 B). Transmission EM confirmed these findings and showed necrosis of numerous cells (Fig. $4 \mathrm{~B}$ ). Pretreatment with either 0.52 - or $2.6-\mu \mathrm{M}$ dose of $\mathrm{dmPGE}_{2}$ signifcantly reduced the extent of indomethacin-induced injury of gland cells as reflected by increased cell viability (Fig. 1), decreased LDH release into the medium (Fig. 2), and decreased ultrastructural damage (Figs. $3 C$ and $4 C$ ) vs. the placebo plus indomethacin group. The higher dose of $\operatorname{dmPGE}_{2}(26 \mu \mathrm{M})$ used as a pretreatment in four gland preparations did not furnish more protection against indomethacin injury compared with the $2.6 \mu \mathrm{M}$ dose (viability $65 \pm 3 \%$ vs. $66.9 \pm 3 \%$; LDH release $12 \pm 1.4$ vs. $11 \pm 1.7)$.

1-h incubation of placebo-pretreated isolated human gastric glands with $8 \%$ ethanol produced significant reduction of cell viability (Table I), significant increase in $\mathrm{LDH}$ release into the medium (Table I), and severe morphologic injury documented by scanning and transmission EM (Figs. $5 B$ and $6 B$ ).

PG pretreatment significantly reduced the extent of ethanol-induced injury of gland cells, increasing cell viability (Table I), decreasing LDH release into the medium (Table I), and decreasing ultrastructural damage when compared with the placebo-pretreated group (Figs. $5 C$ and $6 C$ ).

There was a strong positive linear correlation between cell death assessed by the inability to exclude fast green and LDH release into the medium for both indomethacin $(r=0.95 ; y$ $=3.2+0.29 x)$ and ethanol $(r=0.97 ; y=-4.43+0.56 x)$.

\section{Discussion}

This study demonstrates that either indomethacin or ethanol produces severe damage to isolated human gastric gland cells as evidenced by reduced cell viability, increased LDH release into the medium, and extensive morphologic cell destruction. In in vivo studies, gastric mucosal damage by indomethacin has been attributed to inhibition of mucous secretion (24), inhibition of gastric mucosal PG synthesis $(8,25)$, reduction of mucosal blood flow (8), damage to endothelial cells of the mucosal microvasculature (26), and inhibition of cellular active transport of sodium (9).

Mechanisms ascribed to ethanol injury of gastric mucosa in vivo include surface epithelial exfoliation with loss of "barrier," transport, and electrical functions $(14,27)$ and hemorrhagic necrosis of deeper mucosal layers including the progenitor and glandular cells $(14,27)$. Ethanol-induced damage to endothelial cells occurs within minutes of exposure and results in microvascular stasis. This microvascular injury has been proposed to be an important mechanism responsible for deep mucosal necrosis after ethanol administration $(15,28)$.

PGs protect the gastric mucosa against indomethacin- or ethanol-induced damage in vivo. While some of the morphologic, functional, and temporal features of PGs' mucosal protection in vivo have been characterized $(3-5,14-16,27,28)$, such studies have not ascertained whether this protection is predominantly mediated by systemic factors such as blood flow, hormonal or neural factors, or whether PGs' direct action on the gastric mucosal cells themselves is an important facet of mucosal protection.

By using isolated gastric glands in our experiments we excluded blood flow and extraglandular hormonal as well as neural factors; we therefore studied PGs' direct action on the cells. Our data clearly demonstrated that $\mathrm{dmPGE}_{2}$ exerts a direct protective action on the human gastric mucosal cells in the absence of systemic factors. Preincubation of the human gastric glands with $\mathrm{dmPGE}_{2}$ significantly reduced both indo-

Table I. Viability of Isolated Gastric Gland Cells and LDH Release into the Medium after $1 \mathrm{~h}$ of Incubation

\begin{tabular}{lcc}
\hline \multicolumn{1}{c}{ Groups } & Viability & LDH release \\
\hline & $\%$ & $\%$ \\
A. Placebo & $86 \pm 2$ & $10 \pm 1.7$ \\
B. PG & $89 \pm 2$ & $6 \pm 1$ \\
C. Placebo + 8\% ethanol & $40 \pm 6^{*}$ & $22 \pm 2^{*}$ \\
D. PG + 8\% ethanol & $62 \pm 3^{* \ddagger}$ & $13 \pm 1^{* \ddagger}$
\end{tabular}

The values represent mean \pm SE of eight gland preparations. PG $\left(16,16 \mathrm{dmPGE}_{2}\right)$ dose was $2.6 \mu \mathrm{M}$.

* $P<0.001$ vs. placebo or PG group.

${ }^{\ddagger} P<0.005$ vs. placebo + ethanol group. In addition to direct comparison of absolute values between the groups, the difference (delta) $(A-C)$ was compared with difference $(B-D)$. This was done to account for the possible effect of PG alone on cell viability and LDH release. The $P$ value for this comparison was also statistically significant $(P<0.01)$. 

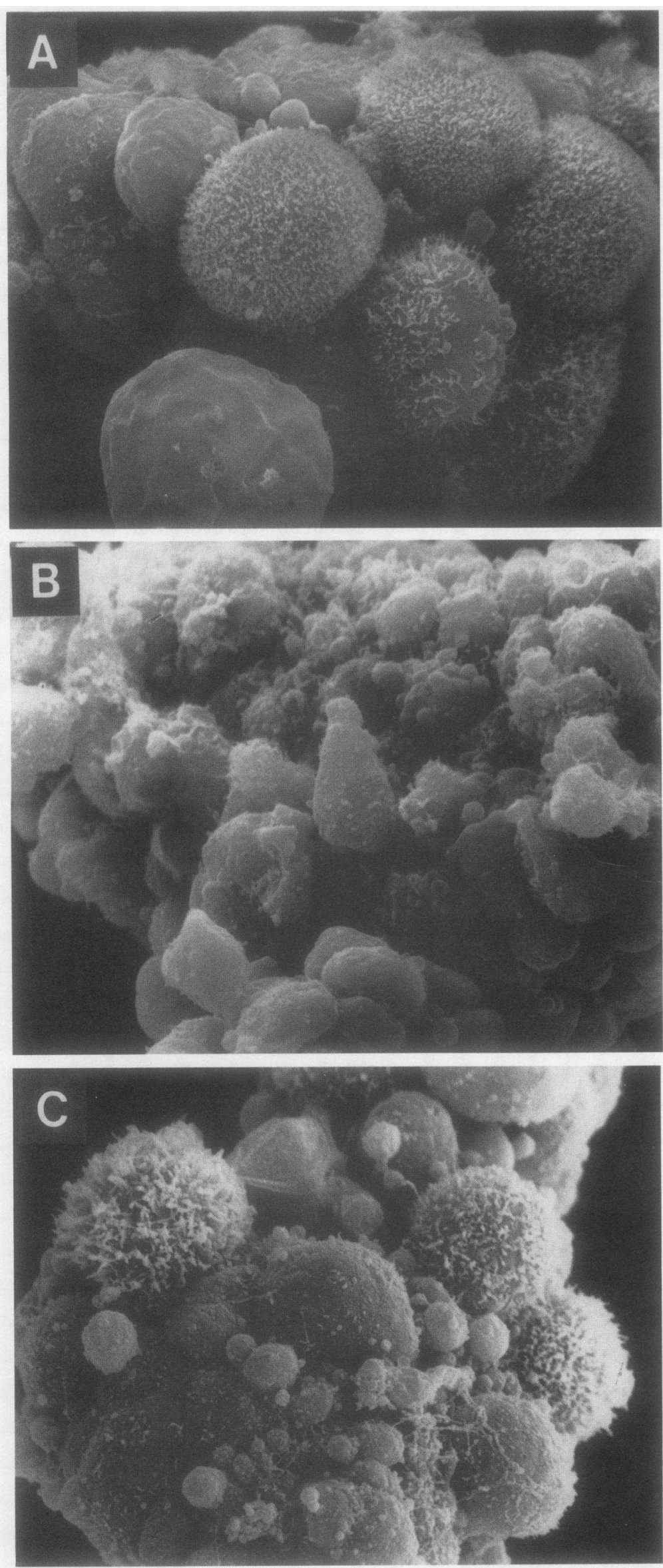

Figure 5. Scanning electronmicrographs of isolated human gastric glands. $(A)$ Control incubated with placebo only. Gland cells are interconnected, round, and either contain numerous microvilli (parietal cells) or are without microvilli (chief cells). (B) Placebo-pretreated glands incubated with $8 \%$ ethanol for $1 \mathrm{~h}$. Changes in cell shape and size (cells are shrunken), loss of microvilli, and disintegration of the cells are clearly visible. $(C)$ PG pretreated and incubated with $8 \%$ ethanol glands. Numerous cells retained shape, size, and microvilli. $\times 2,800$. 

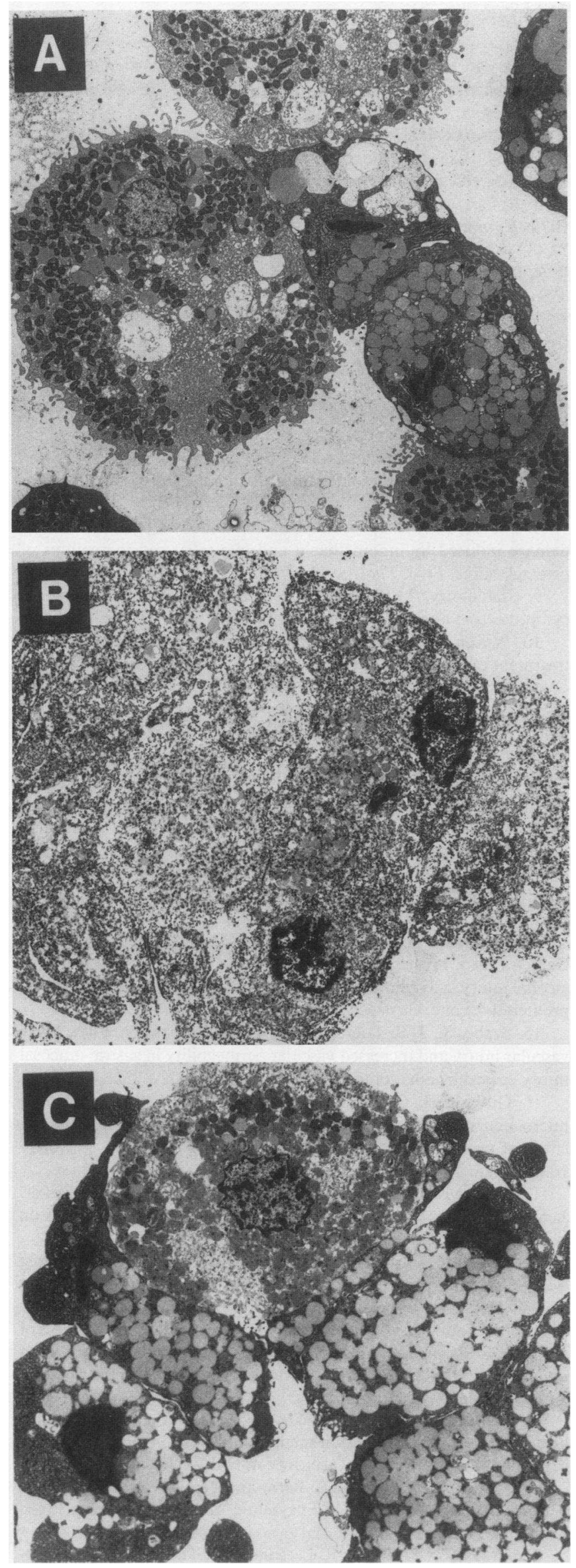

methacin- and ethanol-induced gastric gland cell necrosis, increased the number of viable cells, decreased LDH release into the medium, and reduced the extent of ultrastructural destruction detected by scanning and transmission EM. These findings indicate that dmPGE 2 exerts a direct protective effect on the glandular cells themselves. Such action of PGs may be partly responsible for their protective action in vivo and perhaps for their prophylactic and therapeutic effects in clinical settings (5).

While reduction of indomethacin-induced damage to isolated human gastric glands by $\mathrm{dmPGE}_{2}$ could be due to replacement of depleted mucosal PGs, the protection by dmPGE $_{2}$ against ethanol injury cannot be explained by such a simple mechanism, because ethanol does not inhibit PG synthesis (29). Therefore, PG mucosal protection against injury must include the direct effects of PG on cell membranes or metabolism. The effect of $\mathrm{dmPGE}_{2}$ on the barrier function of the membrane, reflected by both preventing a dye from penetrating the cell and preventing efflux of $\mathrm{LDH}$, may suggest that the cell membrane itself could be a major site of PGs' protective action.

The PG used in our experiment significantly reduced, but did not completely prevent, cell damage. One could ask whether a higher concentration of PG would have offered a greater degree of protection. We explored this question in our previous experiments in isolated rat gastric glands. We found that higher concentrations of dmPGE $2(13$ and $26 \mu \mathrm{M})$ offered a similar degree of protection as did $2.6 \mu \mathrm{M}$, against either indomethacin or ethanol injury. The higher dose of $\mathrm{dmPGE}_{2}$ $(26 \mu \mathrm{M})$ used in our present study did not furnish more protection against indomethacin injury than did $2.6 \mu \mathrm{M}$ $\mathrm{dmPGE}_{2}$. These findings indicate that there is a threshold concentration of $P G$ which offers cell protection. Once the protective threshold concentration is reached, higher concentrations of PG do not offer additional protection.

In this respect, our in vitro data are in agreement with the studies in vivo which showed that even at very high doses, $\mathrm{dmPGE}_{2}$ significantly reduced, but did not completely prevent, gastric mucosal damage (14). Of several different PG (natural $\mathrm{PGE}_{1}, \mathrm{PGE}_{2}$, their synthetic analogues and $\mathrm{PGI}_{2}$ ) we studied in rats, $16,16 \mathrm{dmPGE}_{2}$ had the most potent protective effect on the gastric mucosa. The limited availability of the human gastric surgical specimens narrowed our choice of PG to the most potent PG preparation, which has also been shown to protect the human gastric mucosa in vivo (30).

The concentration of indomethacin used in our study was higher than the concentration used to inhibit PG synthesis (1, 8). Since PG did not completely protect against injury even at higher concentrations, we propose that indomethacin has a direct cytotoxic effect which is entirely or partly independent of its known ability to inhibit PG synthesis. The loss of micro-

Figure 6. Transmission electronmicrographs of isolated human gastric glands. $(A)$ Control incubated with placebo only. Cells are interconnected and display normal appearance of parietal and chief cells. $(B)$ Placebo pretreated and incubated with $8 \%$ ethanol glands. Most of the cells are so severely damaged that an identification of subcellular or cellular structures is impossible. $(C)$ PG pretreated and incubated with $8 \%$ ethanol glands. Although some cells show edema and minor damage, the structural integrity of most of the cells is well preserved. $\times 3,800$. 
villi and changes in cell shape observed after indomethacin or ethanol injury in placebo-pretreated glands suggest that the cell cytoskeleton may be one specific target for the toxic effect of these agents. Since cytoskeletal elements (actin filaments, microtubules, and intermediate filaments) and their associated proteins play an important role in supporting cell structure and shape (31-33), and since indomethacin- or ethanol-induced injury involves changes in cell shape, loss of microvilli, and formation of membrane microblebs, it is reasonable to postulate that indomethacin and ethanol-induced cell injury are due in part to destruction or modification of cytoskeletal elements. Correspondingly, these elements may also be a site of PG-induced protection. This hypothesis must be explored in future studies designed specifically to answer these questions.

The concentrations of indomethacin and ethanol used in these studies were selected on the basis of our previous experiments with isolated rat gastric glands (unpublished data), which showed that these concentrations of indomethacin and ethanol reduced gland viability by $>50 \%$ within $1-2 \mathrm{~h}$. In the present study we found that these concentrations of indomethacin and ethanol had similar toxic effects on isolated human gastric gland cells. In this context, it is interesting that in isolated rat gastric glands, lower concentrations of indomethacin (e.g., 8.8 and $44 \mu \mathrm{M}$, sufficient to inhibit PG synthesis) produced cell swelling and partial gland cell separation but did not affect gastric gland cells viability and LDH release. These findings indicate that a short-term inhibition of PG synthesis does not cause toxic cell injury by indomethacin in our experimental model. This contention is also supported by the fact that alcohol does not inhibit synthesis of PG but produces acute toxic injury of gastric gland cells. These findings indicate that acute toxic injury of gastric gland cells may be independent of PG inhibition.

Abecassis et al. have recently demonstrated that $\mathrm{dmPGE}_{2}$ is able to prevent viral-induced damage to the liver in vivo and to cultured hepatocytes in vitro (34). These experiments indicate that PG can protect hepatocytes directly without systemic mediation, thereby suggesting that the direct protective action of PG is not limited to gastroduodenal cells only, but may be a more general phenomenon.

Finally, in this study we used the fast green exclusion test for assessing cell viability. This method has been used before only to assess the viability of neoplastic cells (20). While it has the same sensitivity as the routinely used trypan blue exclusion test, it has a clear advantage over the latter in precluding the necessity to evaluate wet preparations within a limited time, and the use of counterstaining, which allows better distinction between dead and viable cells.

In summary, this study demonstrates that a synthetic $\mathrm{PGE}_{2}$ analogue is able to protect isolated gastric gland cells against indomethacin or ethanol injury under conditions where vascular and extraglandular neural as well as hormonal factors are excluded. This clearly indicates direct protective action of PG on the cells independent of systemic mediation.

\section{Acknowledgments}

This work was supported in part by research grant RO I AM-32856 from the National Institutes of Health and the Medical Research Service of the Veterans Administration.

\section{References}

1. Peskar, B. M. 1977. On the synthesis of prostaglandins by the human gastric mucosa and its modification by drugs. Biochim. Biophys. Acta. 487:307-314.

2. Konturek, J. S., and W. Pawlik. Gastric acid inhibition by prostaglandins. 1985. In Biological Protection with Prostaglandin. Vol II. M. Cohen, editor. CRC Press. Boca Raton, FL. 45-61.

3. Robert, A., J. E. Nezamis, C. Lancaster, and A. J. Hancher. 1979. Cytoprotection by prostaglandins in rats. Gastroenterology. 77:433-443.

4. Robert, A. 1979. Cytoprotection by prostaglandins. Gastroenterology. 77:761-767.

5. Tarnawski, A. 1980. Cytoprotection. A new fashion or real progress? Pol. Arch. Med. Wewn. 64:97-104.

6. Vane, J. R. 1971. Inhibition of prostaglandin synthesis as a mechanism of action for aspirin-like drugs. Nature New Biol. 231:232-235.

7. Main, I. H. M., and B. J. R. Whittle. 1975. Investigation of the vasodilator and antisecretory role of prostaglandins in the rat gastric mucosa by use of non-steroidal anti-inflammatory drugs. Br. J. Pharmacol. 53:213-224.

8. Whittle, B. J. R. 1977. Mechanisms underlying gastric mucosal damage induced by indomethacin and bile salts, and the actions of prostaglandins. Br. J. Pharmacol. 60:455-460.

9. Chaudhury, T. K., and E. D. Jacobson. 1978. Prostaglandin cytoprotection of gastric mucosa. Gastroenterology. 74:1229-1232.

10. Wilson, D. E. 1986. Therapeutic aspects of prostaglandins in treatment of peptic ulcer disease. Dig. Dis. Sci. 31(Suppl.):425-465.

11. McCall, E., B. J. R. Whittle, and L. I. F. Youlten. 1976. Effects of prostaglandin $E_{2}$ methyl analogues on the anti-inflammatory and gastric erosive activity of indomethacin. J. Pharm. Pharmacol. 28:588-589.

12. Cohen, M. M., and J. M. Pollett. 1976. Prostaglandin $E_{2}$ prevents aspirin and indomethacin damage to human gastric mucosa. Surg. Forum. 27:400-401.

13. Johansson, C., B. Kollberg, R. Nordemar, K. Samuelson, and S. Bergstrom. 1980. Protective effect of prostaglandin $E_{2}$ in the gastrointestinal tract during indomethacin treatment of rheumatic diseases. Gastroenterology. 78:479-483.

14. Tarnawski, A., D. Hollander, J. Stachura, W. J. Krause, and H. Gergely. 1985. Prostaglandin protection of the gastric mucosa against alcohol injury, a dynamic time related process. The role of the mucosal proliferative zone. Gastroenterology. 89:366-374.

15. Szabo, S., J. S. Trier, A. Brown, and J. Schnoor. 1985. Early vascular injury and increased vascular permeability in gastric mucosal injury caused by ethanol in the rat. Gastroenterology. 88:228-236.

16. Guth, P. H., G. Paulsen, and H. Nagata. 1984. Histologic and microcirculatory changes in alcohol-induced gastric lesions in the rat: effect of prostaglandin cytoprotection. Gastroenterology. 87:10831090.

17. Muller-Lissner, S. A., C. Fimmel, A. Sonnenberg, B. Peskar, J. A. Fischer, and A. L. Blum. 1981. The effect of prostaglandins on isolated rat gastric cells. Scand. J. Gastroenterol. 16:229-232.

18. Berglindh, T., and K. J. Obrink. 1976. A method for preparing isolated glands from the rabbit gastric mucosa. Acta Physiol. Scand. 96:150-159.

19. Berglindh, T., H. F. Helander, and K. J. Obrink. 1976. Effect of secretagogues on oxygen consumption, aminopyrine accumulation and morphology in isolated gastric glands. Acta Physiol. Scand. 97:401-414.

20. Weisenthal, L. M., J. A. Marsden, P. L. Dill, and C. K. Macaluso. 1983. Novel dye exclusion method for testing in vitro chemosensitivity of human tumors. Cancer Res. 43:749-757.

21. Bergmeyer, H. U., T. E. Bern, and N. B. Hess. 1965. Lactic dehydrogenase. In Methods of Enzymatic Analysis. Academic Press, Inc., New York. 736-741.

22. Krause, W. J., and C. R. Leeson. 1973. The postnatal develop- 
ment of the respiratory system of the opossum. Light and scanning electron microscopy. Am. J. Anat. 137:337-356.

23. Conover, W. J. 1971. Practical nonparametric statistics. John Wiley \& Sons, Inc., New York. 393.

24. Menguy, R., and L. Desbaillets. 1967. Role of inhibition of gastric mucous secretion in the phenomenon of gastric mucosal injury by indomethacin. Am. J. Dig. Dis. 12:862-866.

25. Whittle, B. J. R. 1981. Temporal relationship between cyclooxygenase inhibition, as measured by prostacyclin biosynthesis, and gastrointestinal damage induced by indomethacin in the rat. Gastroenterology. 80:94-98.

26. Rainsford, K. D., S. A. Fox, and D. J. Osborne. 1984. Comparative effects of some non-steroidal anti-inflammatory drugs on the ultrastructural integrity and prostaglandin levels in the rat gastric mucosa. Relationship to drug uptake. Scand. J. Gastroenterol. 19(Suppl. 101):55-68.

27. Tarnawski, A., D. Hollander, J. Stachura, B. Klimczyk, T. Mach, and J. Bogdal. 1987. Alcohol injury to the normal human gastric mucosa: endoscopic histologic and functional assessment. Clin. Invest. Med. (Can. J. Clin. Invest.) 10:259-263.

28. Tarnawski, A., and D. Hollander. 1985. Ethanol-induced gastric mucosal injury. Sequential analysis of morphologic and functional changes. Gastroenterol. Clin. Biol. 9(bis):88-92.
29. Konturek, S. J., T. Brzozowski, J. Piastucki, T. Radecki, and A. Dembinska-Kiec. 1983. Role of prostaglandin and thromboxane biosynthesis in gastric necrosis produced by taurocholate and ethanol. Dig. Dis. Sci. 28:154-160.

30. Tarnawski, A., D. Hollander, J. Stachura, B. Klimczyk, T. Mach, and J. Bogdal. 1986. Prostaglandin protection of the human gastric mucosa against alcohol-induced injury. Scand. J. Gastroenterol. 21(Suppl. 125):165-169.

31. Weber, K., and M. Osborn. 1981. Microtubule and intermediate filament network in cells viewed by immunofluorescence microscopy. In Cytoskeletal Elements and Plasma Membrane Organization. G. Poste and G. L. Nicolson, editors. Elsevier/North Holland Biomedical Press, New York 1-53.

32. Weeds, A. 1982. Actin-binding proteins-regulators of cell architecture and motility. Nature (Lond.). 296:811-815.

33. Dabike, M., and C. Koenig. 1983. Intermediate filaments of the cytoskeleton in glandular cells of the rat fundic mucosa. Immunofluorescence and electron microscopy study. Anat. Rec. 207:297-308.

34. Abecassis, M., J. A. Falk, L. Makowka, V. J. Dindzans, R. E. Falk, and G. A. Levy. 1987. 16,16 dimethyl prostaglandin $E_{2}$ prevents development of fulminant hepatitis and blocks the induction of monocyte/macrophage procoagulant activity after murine hepatitis virus strain 3 infection. J. Clin. Invest. 80:881-889. 